\title{
HUBERT FICHTE EN EL CHILE DE LA UNIDAD POPULAR: MITAD REVOLUCIÓN SOCIALISTA, MITAD LIBERACIÓN HOMOSEXUAL
}

Nelly Richard 


\section{NELLY RICHARD}

Crítica cultural y ensayista. Fue fundadora y directora de la Revista de Crítica Cultural entre 1990 y 2008. Recibió la Beca Guggenheim en 1996. Es autora de Crítica y política (2013); Feminismo, género y diferencia(s) (2008); y Residuos y metáforas. Ensayos de crítica cultural sobre el Chile de la transición (1998), entre otros libros. 


\section{HUBERT FICHTE EN EL CHILE DE LA UNIDAD POPULAR: MITAD REVOLUCIÓN SOCIALISTA, MITAD LIBERACIÓN HOMOSEXUAL*}

Hubert Fichte es uno de los escritores más singulares de la literatura alemana de posguerra. Su proyecto literario, interrumpido por su muerte temprana en 1986, está hecho de "una prosa autográfica experimental, practicada durante toda su vida, con el intento de pensar nuevamente las ciencias humanas bajo la presión del Holocausto, la bomba atómica, el colonialismo y el hambre global" (Fichte, 2018). La reciente publicación en español del libro Chile: experimento por el futuro -que incluye un fragmento de Explosión, novela de la etnología dedicado al viaje que realizaron a nuestro país Fichte y Leonore Mau en 1971, además de la transcripción de una pieza radiofónica emitida el 9 de septiembre del mismo año en Alemania, con la entrevista de Fichte a Salvador Allende- nos hace preguntarnos por los aportes de lectura y nuevos efectos de sentido que arroja este libro más bien extravagante sobre el periodo de la Unidad Popular. ¿Qué nuevas configuraciones expresivas, qué ángulos de visión y texturas de la experiencia le imprime esta obra a la comprensión de una trama local ya envuelta en su propia historicidad política y social? Lo primero que generan las metáforas quebradas de Fichte es una sensación de extrañeza-extrañamiento (de otredad), que provoca, insolentemente, un desajuste de estilo con el tono glorioso del modo en que los partidarios de la Unidad Popular relatan su toma de conciencia política e ideológica de la épica revolucionaria.

La condición de otredad asociada a este desajuste de percepción y conciencia tiene como origen, sin duda, el hecho de que la obra de Fichte sea, en sí misma, una obra viajera. Lo es, primero, por tratarse de un trabajo en constantes desplazamientos de geografías, identidades, géneros, formatos y técnicas de escritura; una obra que mezcla territorios, civilizaciones y razas debido a la inquietud constante de su autor por salirse de las rutinas y convenciones de lo familiar (lo conocido, lo reconocible), para emprender viajes hacia latitudes remotas y desconocidas. La obra es también viajera en tanto se mueve - desprejuiciadamente- entre lo etnográfico, lo literario y lo periodístico, cambiando de materiales y frecuencias de escritura según las

Este texto fue leído en el marco del coloquio "Suprasensibilidades", organizado por el Goethe Institut en torno a la obra de Hubert Fichte, Museo Nacional de Bellas Artes, 14 de septiembre de 2018 
circunstancias: "El novelista que quería convertirse en etnólogo, aterriza otra vez como periodista" (íbid.: 12). La obra de Fichte es viajera, además, porque registra los tránsitos de una sexualidad híbrida que ocupa la ambigüedad como falso pasaporte para mutar de rasgos al ritmo de sus deambulaciones por países y ciudades cuyos reversos más enredados le inquietan y seducen.

Quien viajó a Chile en junio y julio de 1971 para conocer de cerca la experiencia de la Unidad Popular fue un Fichte que se describía a sí mismo como "el homosexual viajero" (íbid.: 52). Un Fichte que mezclaba sus anotaciones periodísticas sobre la realidad nacional con el relato de sus derivas homoeróticas por las calles de Santiago de Chile, donde se sentía irresistiblemente atraído por los placeres más escondidos de los submundos. La curiosidad científica del etnólogo, el afán de precisión del periodista que recopila datos a veces menores y la motivación estética del literato aficionado a la plasticidad del lenguaje convergen en un mismo gusto por los "detalles", es decir, por aquellos fragmentos que se salen de la visión de conjunto del plano general para llamar la atención sobre lo insólito de aquello que deforma la visión basada en la geometría plana de una relación calculable entre la parte y el todo. Este gusto por "los detalles que pueden desaparecer o aumentan excesivamente" (íbid.: 82) hace que el relato de Fichte que narra su primer contacto con Santiago de Chile esté plagado de observaciones microscópicas que convierten a la ciudad en un mosaico de percepciones diminutas: "Movilidad y ropa bien planchada: esto es lo que se ve... Los enamorados en el parque tienen libros en la mano... Los mendigos golpetean incansablemente con sus tazones de loza" (ibid.: 57-58). Fichte repara en la decoración de interiores de ciertos lugares de encuentros sexuales: "Se dice que el hotel Foresta le pertenece al rey del porno de Santiago. Es como un alhajero que imita al estilo rococó. El ascensor está forrado de felpa roja" (íbid.: 59), o bien, "El hotel Valdivia ha logrado ser mencionado en la revista Times. Una pensión de lujo con una tendencia ilusionista. Amor por horas en grutas, en Arabia, apartamentos renacentistas" (ibid.: 92). También asoma la extravagancia del retoque cosmético de las sexualidades invertidas: "En Valparaíso, hay burdeles populares con travestis. Los trabajadores hablan entusiasmados sobre el maquillaje que suele ser muy humilde: ¡cejas punteadas y pestañas de papel!” (íbid.: 86). Lo ornamental de estos pequeños detalles (suntuarios, digresivos, adyacentes) descoloca la narrativa monumental (totalizante, centralizante y finalizante) de cómo la Historia elige recitarse a sí misma confiada en la superioridad de un dominio de conocimiento que se dice completo. Esta ilusión de completitud tiene que ver con el dominio imponente de lo masculino, que pretende abarcarlo todo en su gesta heroica. En Fichte, la opción fantasiosa por lo ornamental de los detalles pintorescos o novelescos versus lo monumental del guion político-social de la Historia delata aquella tensión entre lo público y lo privado, lo mayúsculo y lo minúsculo, lo esencial y lo prescindible, es decir, entre lo masculino 
(rectitud, peso) y lo femenino (sinuosidad, ligereza) que escinde el imaginario cultural de las grandes revoluciones, con sus conflictos de registros de valor y representación entre lo estético, lo político, lo ideológico y lo sexual.

Las notas de Fichte sobre Santiago — "palimpsesto de la metamorfosis política" (ibid.: 29)— se desvían fácilmente hacia "los saunas, parques, hoteles" (íbid.: 66) como zonas de recreación sexual donde los cuerpos y las sexualidades se olvidan por un rato de que, afuera, la sociedad entera está motorizada por un deseo histórico de cambios sociales que exigen un compromiso colectivo. Fichte reconoce su adhesión al proyecto de la Unidad Popular y a su "joven gobierno": "Jacki (alter ego de Fichte en la novela) en estos meses se decidió por el socialismo, un socialismo sin duda muy particular"(ibid.: 26). Sin embargo, Fichte deja claro que este compromiso colectivo del pueblo de Chile con el gobierno de Salvador Allende al que adhiere no tiene por qué arrastrar a la literatura que simpatiza con su revolución a cumplir con la obediencia de forma y contenido que exige el arte militante: "No existe la literatura comprometida, piensa Jacki. El criterio de la literatura es que no se compromete" (ibid.: 14). Fichte no se resigna a que la literatura ocupe la función ilustrativa que subordina la forma del texto (licencias creativas) a la ideología del mensaje (dogmatismo del principio rector). La obra heteróclita de Fichte desajusta la sintaxis, revuelve el fondo de la palabra para extraer de ella una sustancia lingüística rebelde a toda programaticidad de conciencia. Para la literatura de Fichte, no existe otro compromiso que el de agitar los sentidos hasta experimentar rítmicamente con lo inédito, incluyendo como materia la sexualidad y sus desenfrenos.

La izquierda libertaria con la que se identifica Fichte quiere mezclar las luchas de intereses (sociales y políticos) que guían al colectivo con las luchas individuales (luchas de deseo) que aspiran a una vida sexualmente independiente del conjunto de normas que sujetan y aprisionan al cuerpo a una moralidad y sociabilidad obligadas. Al negarse a elegir entre el principio de realidad y el principio de placer, se pregunta Fichte: "De qué serviría proporcionarles un litro de leche por día a los niños (la campaña de salud pública de Salvador Allende) si se les va a meter a presión el mismo odio, la misma aversión hacia la voluptuosidad, el mismo desprecio por el amor y el cuerpo que rigen hace 2000 años" (ibid.: 29). Desde este vitalismo integral que considera a la liberación sexual (lo corporal, lo erótico, lo libidinal) como pieza clave de la desenajenación del sujeto de la productividad capitalista, Fichte cuestiona la represión del deseo ejercida por la moral revolucionaria que le teme al desate de los sentidos. En su novela, el autor consigna, audazmente, que "lo que Jacki quería saber principalmente en Chile era si un régimen socialista, que les daba un litro de leche por día a los niños hambrientos, les había concedido su octava partecita de crema a los maricones" (íbid.: 26). Por un lado, está la responsabilidad social de una revolución contra la desnutrición infantil y, por otro, la demanda de reconocimiento 
del placer homosexual como revolución del deseo. Consciente de que el ideal revolucionario se afirma en el patrón de la virilidad, de la masculinidad combativa ("Carlos Jorquera, un macho socialista"), Fichte no puede dejar de preguntarse, en su interior, cuando entrevista a algún personero de la Unidad Popular, cuáles son las vías alternas por donde circulan ocultamente la fantasía, el placer y el deseo sexual que el credo revolucionario inhibe en cada uno de ellos debido a la extrema politización de la vida social que satura la exterioridad pública con sus marchas, asambleas y concentraciones del pueblo. Al entrevistar a Jacques Chonchol, el ministro de la reforma agraria, se pregunta, impertinentemente, si "نes posible que conozca el vicio?” (íbid.: 100). Una pregunta licenciosa para cualquier digno representante de la revolución del "hombre nuevo", con su idealización masculina de una conducta enteramente volcada hacia las transformaciones económicas y políticas de la revolución social. La impertinencia de la pregunta es proporcional a la manera en que la moral revolucionaria condena, por burguesa y desviacionista, cualquier turbulencia erótica.

Tal como lo lamenta Fichte, la Unidad Popular dejó que se expresaran los prejuicios del discurso homofóbico en los titulares ofensivos de los diarios izquierdistas Puro Chile o El Clarín, que hablaban de "maracas" o de "yeguas sueltas", con burla y desprecio. Fichte confiesa en sus escritos la pregunta que no alcanzó a hacerle a Salvador Allende antes de que se acabara el tiempo de la entrevista que le fue oficialmente concedida: "Ya no hay más minutos. Para mí, habría sido importante preguntarle... ¿por qué tolera que en Puro Chile, un periódico de la Unidad Popular, se persiga a los homosexuales?” (ibid.: 120-121). Desde ya, una pregunta como esta no se le hubiese ocurrido nunca a Régis Debray en su famosa conversación privada con el "compañero presidente" (1971), una conversación que gira ortodoxamente en torno al marxismo, la lucha de clases y la conquista del poder de Estado. Esta sería otra prueba más de cómo el imaginario masculino-revolucionario de la izquierda latinoamericana desatiende los temas de la subjetividad y del inconsciente, del cuerpo y de la sexualidad, por considerar que estos pertenecen al ámbito burgués de lo privado y que, por lo mismo, no merecen ser incorporados al discurso universal de la emancipación proletaria. Fichte resume su viaje a Chile diciendo que, "en estos dos meses, se decidió por el socialismo". Al mismo tiempo, recalca que esta elección política y social no implica renunciar en lo más mínimo a los tumultos de la promiscuidad sexual: "Jacki... no había retrocedido en poner al mismo nivel el litro de leche para los niños hambrientos y la porcioncita de crema para el maricón hambriento" (íbid.: 50). Esta no-renuncia de Fichte al placer de los cuerpos relegados al secreto por la superioridad moral del "deber ser" de la revolución socialista nos llama hoy a revisar la relación de suspicacias y desencuentros entre el ideario de la izquierda y los revuelos homosexuales. 
La obra de Hubert Fichte ha sido revalorizada últimamente en la escena internacional debido al auge de los estudios queer, que reconocen tanto en su persona como en sus escritos la figura retorcida de una sexualidad disidente. No costaría nada releer a Fichte desde las claves de este repertorio metropolitano de los estudios queer que buscan traspasarnos sus categorías discursivas a través de la máquina globalizada de la reproducción académica que, entre otras latitudes, ha colonizado también a Chile. Pero esta relectura queer de la obra de Fichte supone el riesgo de fallarle al principio de "regionalismo crítico" como necesidad de ir dibujando mapas locales - e historizados - de la disidencia sexual latinoamericana. Más que cruzar la relectura de la obra de Fichte en Chile con las bibliografías internacionalizadas de lo queer, creo importante hacerla dialogar con aquellos escritos que, desde Chile, ya se habían propuesto indagar en los pliegues de contradicción que separan el dogma izquierdista de las pulsiones tránsfugas de una homosexualidad en ruptura de molde y género. Como parte de este corpus están Hablo por mi diferencia de Pedro Lemebel (1986); Bandera bueca. Historia del movimiento homosexual en Chile de Víctor Hugo Robles (1992); y Nación marica. Prácticas culturales y crítica activista de Juan Pablo Sutherland (2009); y El deseo invisible. Santiago antes del golpe de Gonzalo Asalazar (2017), entre otros escritos. Las estructuras de la sensibilidad develadas por la obra de Fichte en su encuentro con el Chile de la Unidad Popular son afines a este diagrama de pulsiones nómades que el pensamiento de izquierda debe tomar en cuenta para que el devenir otro(a) de subjetividades en proceso sea parte de las aspiraciones emancipadoras de sus microrrevoluciones. 


\section{REFERENCIAS}

Fichte, H. (2018). Chile: experimento por el futuro. Santiago: Metales Pesados. 